\title{
LIST OF AVAILABLE DOCUMENTS
}

\section{TIPSTER SE/CM \\ tipster@tipster.org}

\section{PUBLISHED MATERIAL}

The following additional background information from TIPSTER Text Phases I and II can be purchased from the sources indicated.

\section{Proceedings of the TIPSTER Text Program} (Phase I)

Order number ISBN 1-55860-337-9 from:

Morgan Kaufman Publishers, Inc.,

340 Pine St., 6th Floor,

San Francisco, CA 94104.

$1-800-745-7323$

(415) $578-9928$

fax (415) 578-0672

Email orders@mkp.com

Proceedings of the Fifth Message

Understanding Conference (MUC- 5)

Order number ISBN 1-5860-336-0 from:

Morgan Kaufman Publishers, Inc.,

340 Pine St., 6th Floor,

San Francisco, CA 94104.

1-800-745-7323

(415) $578-9928$

fax (415) 578-0672

Email orders@mkp.com

Proceedings of the Third Text REtrieval Conference (TREC-3).

Ask for NIST Special Publication 500-225,
Proceedings of the Fourth Text REtrieval Conference (TREC-4).

The Proceedings are available (as they are received) at.

http://potomac.ncsl.nist.gov/trec

\section{TIPSTER Text Phase I Data Extraction Collection}

This information includes Template Definitions and Fill Rules for Joint Ventures (JV) for both English and Japanese, and is available by FTP from NMSU/CRL.

\section{TIPSTER Text Phase I Document Detection Collection}

This is the full TIPSTER Text collection used in TREC evaluations and for Document Detection. It is available for purchase in electronic form from the Linguistic Data Consortium (LDC). Call (215) 898-0464; or Email Idc@unagi.cis.upenn.edu. 